\title{
ANALISIS BAURAN PEMASARAN DAN PELAYANAN YANG MEMPENGARUHI KEPUTUSAN PEMBELIAN KONSUMEN DI STARBUCKS BEACHWALK MALL, BADUNG
}

\author{
Nadya Kirana $\mathrm{A}^{1}$, A. A. P. Agung Suryawan W. ${ }^{2}$, Amna Hartiati ${ }^{2}$ \\ ${ }^{1}$ Mahasiswa Jurusan Teknologi Industri Pertanian, Fakultas Teknologi Pertanian Unud \\ ${ }^{2}$ Dosen Jurusan Teknologi Industri Pertanian, Fakultas Teknologi Pertanian Unud \\ Email: nadyakirana44@gmail.com ${ }^{1}$ \\ Email koresponden: agung_suryawan@unud.ac.id²
}

\begin{abstract}
The objectives of research were to determine the factors of marketing mix and service that influenc consumer purchase/buying decisions at Starbucks Beachwalk Mall in Badung and determine the dominant variables that represent every factors influencing purchasing decisions at Starbucks Beachwalk Mall in Badung. Data collection was conducted by distributing 72 questionnaires to the respondents. The data obtained was analyzed using factor analysis method. The results show that there were 8 factor by, namely factor 1 is formed by 4 variables: the accuracy of promotional targets, access, promotion quality, timely service with eigenvalue of 3.179. Factor 2 consists of 4 variables: attractive product appearance, attractive packaging, discount, accurate service with eigenvalue value of 2,296. Factor 3 is formed by 3 variables: proper time of promotion, affordability, spacious parking lot, safe and comfortable with an eigenvalue value of 1.760. Factor 4 is formed by 2 variables: price equilibrium with product quality, business location can be seen clearly from normal distance with eigenvalue value of 1.449. Factor 5 is formed by 2 variables: the existence of other support services, ease of service with eigenvalue value of 1.416. Factor 6 is formed by 2 variables: good taste of coffee, specialty coffee products with eigenvalue value of 1.173 . Factor 7 is formed by 2 variables: promotion quantity, polite and friendly service with eigenvalue value of 1.078. Factor 8 is formed by 2 variables: convenience of getting service, promotion of sales through promotion media with value eigenvalue equal to 1,000
\end{abstract}

Keywords: Factor analysis, marketing mix, purchase decisions, starbucks coffee

\section{PENDAHULUAN}

Pada era globalisasi, masyarakat dituntut untuk mengikuti perubahan sekecil apapun, termasuk perubahan gaya hidup. Contohnya, yaitu gaya hidup mengkonsumsi kopi yang semakin meningkat. Kopi merupakan salah satu jenis minuman hasil pertanian yang digemari oleh sebagian besar penduduk dan sudah menjadi gaya hidup untuk meminum kopi. Di kota-kota besar menikmati kopi sudah menjadi hal yang lumrah.

Kopi sangat mudah dicari, mulai dari warung kopi di pinggir jalan, kedai kopi, maupun di hotel berbintang. Kedai kopi di Indonesia mulai banyak ditemui, dari yang ada di pelosok desa sampai di pusat kota. Setiap tempat menyediakan kopi dengan jenis kopi, pelayanan dan harga kopi yang variatif. Salah satu kedai kopi yang menjadi pilihan konsumen di kota besar adalah Starbucks. Berdasarkan web resminya, Starbucks merupakan kedai kopi global terbesar di dunia dan tersebar di berbagai negara yang berasal dari Amerika Serikat dan berkantor pusat di Seattle, Washington. Kedai kopi tersebut menyediakan berbagai pilihan minuman kopi, biji kopi, minuman panas dan dingin, sandwich, kue kering, camilan, dan barangbarang merchandise seperti cangkir dan tumbler. 
Di Bali, khususnya di Beachwalk Mall, Starbucks menjadi kedai kopi yang diminati para pengunjung. Kedai kopi ini selalu ramai oleh konsumen setiap harinya baik siang ataupun malam hari dengan rata-rata konsumen 250 orang per hari. Selain rasa kopi yang nikmat, Starbucks juga sering memberikan berbagai promo menarik untuk memikat konsumennya, sehingga sering menjadi pilihan untuk menikmati kopi sembari bersantai, berkumpul dengan teman, bersosialisasi, memperluas jaringan, bahkan menjadi tempat untuk melakukan perbincangan bisnis.

Beberapa penelitian sebelumnya mengatakan bahwa variabel-variabel pada bauran pemasaran dan pelayanan sangat berpengaruh terhadap volume penjualan Indriyani (2002). Sudarsana (2007) menyatakan bahwa dari 27 variabel yang diidentifikasi, 24 diantaranya yang tergabung dalam 8 faktor mampu menjelaskan faktor-faktor yang dipertimbangkan konsumen dalam keputusannya untuk berbelanja di supermarket. Berdasarkan uraian diatas, maka perlu dilakukan penelitian tentang analisis bauran pemasaran dan pelayanan yang mempengaruhi keputusan pembelian konsumen di Starbucks Beachwalk Mall Badung untuk meningkatkan kinerja perusahaan dalam memberikan kepuasan kepada konsumen.

Metode analisis faktor dipilih sebagai metode yang dapat mereduksi variabel-variabel yang ada sehingga dapat ditemukan faktor-faktor yang mempengaruhi keputusan pembelian konsumen di Starbucks Beachwalk Mall Badung.

\section{METODE PENELITIAN}

\section{Tempat dan Waktu Penelitian}

Penelitian ini dilakukan di kedai kopi Starbucks Beachwalk Mall Badung yang bertempat di Jalan Pantai Kuta, Kabupaten Badung, Bali. Pelaksanaan penelitian berlangsung pada bulan Agustus - September 2017.

\section{Tahapan Penelitian}

Penelitian tahap pertama yang dilakukan adalah penentuan dan penggolongan variabel-variabel keputusan pembelian konsumen utnuk bauran pemasaran dan layanan, serta penyusunan kuisioner. Setelah menyusun kuisioner, dilakukan pengujian validitas dan reliabilitas terhadap kuisioner tersebut. Pengujian validitas dan reliabilitas ini sangat penting dilakukan karena bertujuan untuk mengetahui sejauh mana suatu alat ukur dapat dipercaya serta sejauh mana alat ukur dapat mengukur yang ingin diukur. Apabila setelah diuji kuisioner ternyata tidak valid dan reliabel, maka dilakukan revisi terhadap kuisioner dan pengujian kembali. Apabila kuisioner yang telah diuji telah valid dan reliabel maka penelitian ini dilakukan ke tahap selanjutnya yaitu penentuan populasi dan sampel menggunakan metode Slovin. Di lokasi penelitian selanjutnya data dikumpulkan dan dianalisis menggunakan program SPSS Versi 22.0 dan Microsoft Excel. Metode yang dilakukan dalam penelitian ini adalah Analisis Faktor. Setelah analisis data, didapatkan variabel-variabel yang dianggap penting, variabel prioritas serta tingkat keputusan pembelian konsumen terhadap bauran pemsaran dan pelayanan. 


\section{HASIL DAN PEMBAHASAN}

\section{Uji Validitas dan Reliabilitas}

Uji validitas berfungsi untuk menguji suatu alat pengukur mampu mengukur yang ingin diukur (Nurdiansyah, D. 2014). Uji validitas pada penelitian ini dilakukan dengan menyerahkan instrumen penelitian (kuisioner) kepada 30 orang responden di Mangsi Coffee, kemudian data yang diperoleh diolah dengan program SPSS versi 22.0. variabel-variabel tersebut dapat dikatakan valid apa bila hasil korelasi tersebut positif dan lebih besar dari 0,300 (Sugiyono, 2008). Berdasarkan hasil uji validitas yang sudah dilakukan, telah didapatkan hasil diatas 0,300 , sehingga semua variabel yang digunakan dapat dinyatakan valid. Hasil uji validitas disajikan pada Tabel 1.

Tabel 1. Uji Validitas

\begin{tabular}{lcl} 
Butir Pertanyaan & Nilai Korelasi Variabel & Keterangan \\
\hline X1 & 0,560 & Valid \\
X2 & 0,803 & Valid \\
X3 & 0,865 & Valid \\
X4 & 0,641 & Valid \\
X5 & 0,888 & Valid \\
X6 & 0,693 & Valid \\
X7 & 0,819 & Valid \\
X8 & 0,551 & Valid \\
X9 & 0,607 & Valid \\
X10 & 0,474 & Valid \\
X11 & 0,590 & Valid \\
X12 & 0,876 & Valid \\
X13 & 0,666 & Valid \\
X14 & 0,828 & Valid \\
X15 & 0,598 & Valid \\
X16 & 0,632 & Valid \\
X17 & 0,724 & Valid \\
X18 & 0,581 & Valid \\
X19 & 0,624 & Valid \\
X20 & 0,838 & Valid \\
X21 & 0,590 & Valid \\
\hline S1
\end{tabular}

Sumber: Uji Validitas

Nilai uji reliabilitas dapat dilihat dari nilai yang ditunjukan oleh Cronbach's Alpha dengan bantuan program SPSS versi 22.0., variabel-variabel dapat dinyatakan reliabel jika nilai yang diperoleh 0,6 (Malholtra, 1999). Hasil uji reliabilitas pada penelitian ini menujukkan nilai Cronbach's Alpha sebesar 0,946. Hasil ini menujukkan bahwa instrumen penelitian (kuisioner) reliabel karena nilai yang dihasilkan lebih besar dari 0,6 .

\section{Analisis Faktor}

Data-data yang telah diperoleh diolah dengan metode analisis faktor menggunakan bantuan program SPSS versi 22.0 dan menghasilkan matriks korelasi. Matriks korelasi dapat mengidentifikasi variabelvariabel yang saling berhubungan dengan ketentuan nilai determinasi yang mendekati nol, nilai KMO 
(Kaiser Mayer Oikin) harus lebih besar daripada 0,5. Uji Bartlett dengan signifikan mendekati nol dan uji MSA harus menujukkan hasil diatas 0,5.

a. Nilai Determinasi Matriks Korelasi

Malholtra (1999) menyatakan, jika angka dari nilai matriks korelasi semakin dekat dengan nol, maka hal ini menunjukkan bahwa antar variabel terbukti saling berkaitan. Nilai determinasi matriks korelasi yang diperoleh menujukkan angka yang mendekati nol, yaitu sebesar 0,013, hal ini menunjukkan bahwa antar variabel terbukti saling berhubungan/berkolerasi.

\section{b. $\quad$ Uji KMO (Kaiser Mayer Oikin)}

Menurut Malholtra (1999), nilai uji KMO harus lebih besar dari 0,5 untuk membuktikan sampel telah cukup untuk difaktorkan. Nilai yang diperoleh dari hasil analisis uji KMO adalah sebesar 0,597. Hal ini menjelaskan bahwa jumlah sampel yang digunakan sudah termasuk baik dan mencukupi.

\section{c. Uji Bartlett}

Agar model faktor dapat digunakan, nilai signifikan yang harus diperoleh pada uji Bartlett adalah < 0,05 (Malholtra, 1999). Hasil uji Bartlett pada hasil analisis diperoleh nilai statistic sebesar 390,030 dengan signifikasi 0,000. Hasil ini menujukkan bahwa antar variabel terjadi korelasi dan peluang kesalahan antar variabel tidak saling independen adalah sebesar 0\% sehingga model faktor dapat digunakan.

\section{d. Uji MSA}

Variabel-vairabel dapat digunakan ke dalam model dan dilakukan analisis lebih lanjut apabila nilai yang diperoleh dari hasil uji MSA $\geq 0,5$ (Santoso, 2006). Hasil Uji MSA menunjukkan hasil, dari 21 variabel yang diamati ternyata tidak terdapat variabel yang harus dikeluarkan dari model karena telah memenuhi kriteria MSA $\geq 0,5$. Setelah melihat masing-masing nilai empat besaran yaitu nilai determinan matriks korelasi, uji KMO, uji Bartlett, dan uji MSA yang telah memenuhi persyaratan analisis faktor, maka analisis faktor dapat dilanjutkan.

\section{e. Menentukan jumlah faktor}

Ekstraksi faktor adalah tahapan selanjutnya untuk menentukan jumlah faktor yang terbentuk didasarkan pada total eigenvalues, percentage of variance, dan cumulative percentage. Suatu faktor dapat menjadi suatu pertimbangan keputusan pembelian konsumen berdasarkan pada eigenvalue yang menunjukkan nilai diatas > 1,0 (Malholtra, 1999), jika didasarkan pada percentage of variance harus memiliki nilai $>5 \%$. Apabila terdapat faktor yang memiliki percentage of variance diatas $5 \%$ maka faktor tersebut dapat digunakan dalam model. Jika didasarkan pada cumulative percentage nilai minimum yang dipenuhi adalah 60\%. Batasan ini ditunjukkan pada hasil analisis faktor. Terdapat 8 faktor yang dipertimbangkan konsumen dalam keputusannya berbelanja di Starbucks Beachwalk Mall, Badung. 
Kedelapan faktor tersebut mampu menjelaskan semua varian yang ada dalam data sebesar $63,57 \%$, seperti terlihat dalam Tabel 2.

Tabel 2. Hasil Ekstraksi Faktor

\begin{tabular}{llll}
\hline Faktor & Eigenvalue & \% of Variance & Cumulative \% \\
\hline 1 & 3,179 & 15,13 & 15,13 \\
2 & 2,296 & 10,93 & 26,07 \\
3 & 1,760 & 8,38 & 34,45 \\
4 & 1,449 & 6,89 & 41,35 \\
5 & 1,416 & 6,74 & 48,09 \\
6 & 1,173 & 5,58 & 53,68 \\
7 & 1,078 & 5,13 & 58,81 \\
8 & 1,000 & 4,76 & 63,57 \\
\hline
\end{tabular}

Sumber: data primer diolah

f. Rotasi Faktor

Sebelum dilakukan rotasi faktor, faktor matriks menunjukkan faktor yang tidak sederhana strukturnya, sehingga masih sulit untuk diinterpretasikan, oleh karena itu dilakukan rotasi faktor untuk memperoleh struktur yang sederhana sehingga mudah untuk menjelaskan seluruh faktor yang dianalisis dalam model. Rotasi faktor yang digunakan dalam penelitian ini ialah rotasi varimax.

g. Interpretasi Faktor

Interpretasi faktor dilakukan dengan mengelompokkan variabel-variabel yang memiliki factor loading tinggi ke dalam faktor tersebut. Factor loading mengidentifikasi korelasi antara variabel dengan faktor yang bersangkutan. Semakin tinggi factor loading maka semakin erat hubungan antar variabel tersebut. Penentuan tingkat minimum factor loading dalam analisis faktor bersifat relatif dan tidak ada ketentuan bersifat baku. Hasil interpretasi penelitian ini factor loading yang kurang dari 0,4 dikeluarkan dari model.

Pada Tabel 3 dapat dilihat ke 21 variabel yang tersebar ke dalam delapan faktor yang merupakan variabel-variabel yang dipertimbangkan konsumen dalam keputusan pembeliannya di Starbucks Beachwalk Mall, Badung.

Tabel 3. Hasil Interpretasi Faktor

\begin{tabular}{clcc}
\hline Faktor & \multicolumn{1}{c}{ Variabel } & $\begin{array}{c}\text { Faktor } \\
\text { Loading }\end{array}$ & $\begin{array}{c}\text { Eigenv } \\
\text { alue }\end{array}$ \\
\hline $\begin{array}{c}\text { Faktor 1 } \\
\text { Kombinasi Lokasi, } \\
\text { Promosi, Pelayanan }\end{array}$ & $\begin{array}{l}\text {-Ketepatan sasaran promosi sudah sesuai } \\
\text { atau tepat sasaran (X15) }\end{array}$ & 0,775 & 3.179 \\
& $\begin{array}{l}\text {-Akses, yaitu lokasi mudah dijangkau } \\
\text { menggunakan sarana transportasi umum } \\
\text { (X8) }\end{array}$ & 0,676 \\
& $\begin{array}{l}\text {-Kualitas promosi yang dilakukan menarik } \\
\text { minat konsumen untuk membeli (X12) }\end{array}$ & 0,624 \\
& $\begin{array}{l}\text {-Pelayanan yang tepat waktu meliputi waktu } \\
\text { tunggu dan waktu proses (X16) }\end{array}$ & 0,425 \\
\hline Faktor 2 & $\begin{array}{l} \\
\text {-Penampilan penyajian produk yang } \\
\text { Hombinasi Produk, }\end{array}$ & 0,862 & 2.296 \\
\hline menarik (X3) & & \\
\hline -Kemasan yang menarik (X4) & 0,747 \\
\hline
\end{tabular}




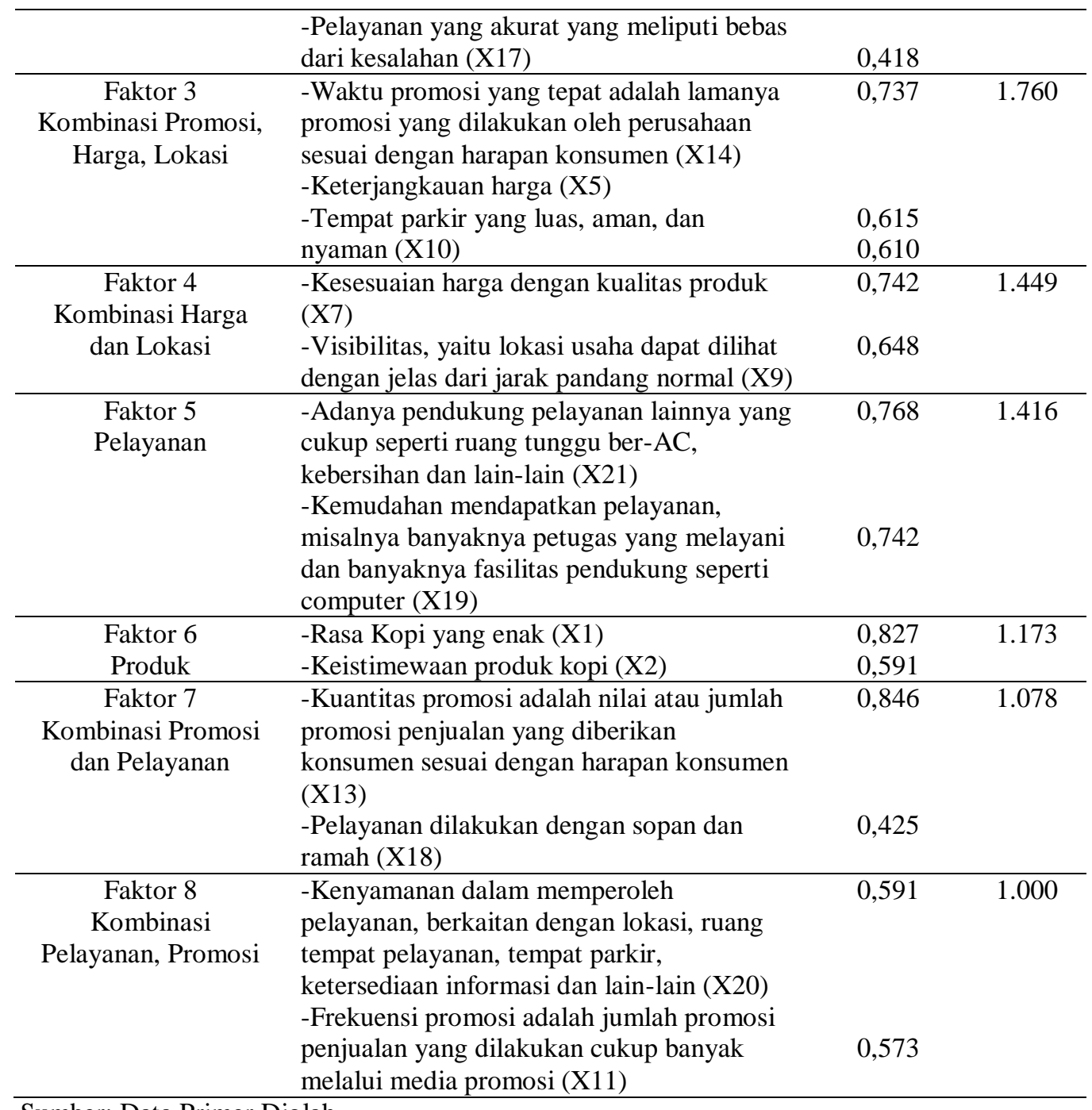

Sumber: Data Primer Diolah

a. Faktor 1. (kombinasi lokasi, promosi, pelayanan)

Ketepatan sasaran promosi sudah sesuai atau tepat sasaran, kualitas promosi yang dilakukan menarik konsumen untuk membeli, akses yaitu lokasi yang mudah dijangkau menggunakan sarana transportasi umum, serta pelayanan yang tepat waktu meliputi waktu tunggu yang diberikan perusahaan merupakan faktor yang dipertimbangkan konsumen dalam keputusannya dalam membeli produk kopi di Starbucks Beachwalk Mall, Badung. (Eigenvalue yang ditunjukkan sebesar 3.179). Variabel-variabel yang tercakup ke dalam faktor 1 ini mampu menjelaskan keragaman variabel sebesar 15,13\%, jika dilihat dari faktor loading. Variabel X15 (Ketetapan sasaran promosi sudah sesuai atau tepat sasaran) merupakan faktor yang dipertimbangkan konsumen terhadap keputusan pembeliannya pada Starbucks Beachwalk Mall, Badung dengan menunjukkan nilai sebesar 0,775. Kemudian pada variabel X8 (Akses, yaitu lokasi mudah dijangkau menggunakan sarana transportasi umum). Lokasi yang terletak di dalam Mall Beachwalk merupakan faktor yang dipertimbangkan dalam keputusan pembelian konsumen. Hal ini ditunjukkan dengan nilai faktor loading sebesar 0,676. Pada faktor X12 (Kualitas promosi yang dilakukan menarik minat konsumen untuk membeli). Promosi yang dilakukan Starbucks menarik minat konsumen juga merupakan faktor yang 
dipertimbangkan konsumen dalam pengambilan keputusan pembelian dengan menunjukkan nilai faktor loading sebesar 0,624. Kemudian disusul dengan variabel X16 (Pelayanan yang tepat waktu meliputi waktu tunggu dan waktu proses). Pelayanan yang dilakukan Starbucks Beachwalk Mall termasuk faktor yang dipertimbangkan konsumen dalam pengambilan keputusan pembelian konsumen dengan nilai faktor loading sebesar 0,425 .

Menurut penelitian Ramdhani (2005), variabel pelayanan dan promosi merupakan penting oleh konsumen dalam melakukan pengambilan keputusan pembelian, dimana dalam penelitiannya disebutkan bahwa kepuasan yang dirasakan konsumen juga berasal dari kualitas pelayanan yang tepat waktu oleh pihak KFC. Hal ini menujukkan variabel pelayanan yang tepat waktu meliputi waktu tunggu berpengaruh dalam pengambilan keputusan pembelian yang dilihat dari hasil penelitian yang diperoleh dan dibandingkan dengan hasil penelitian lain.

b. Faktor 2 (kombinasi produk, harga, pelayanan)

Penampilan penyajian produk yang menarik, kemasan yang menarik, adanya diskon harga produk, serta pelayanan yang akurat yang meliputi bebas dari kesalahan merupakan faktor yang dipertimbangkan konsumen dalam keputusannya untuk membeli produk kopi di Starbucks Beachwalk Mall, Badung. (Eigenvalue yang ditunjukkan sebesar 2.296). variabel-variabel yang tercakup ke dalam faktor-faktor ini mampu menjelaskan keragaman variabel sebesar $10,93 \%$ jika dilihat dari faktor loading. Variabel X3 (Penampilan penyajian produk yang menarik) merupakan faktor yang dipertimbangkan konsumen dalam pengambilan keputusan pembeliannya di Starbucks Beachwalk Mall, Badung dengan menunjukkan nilai sebesar 0,862, hal ini sesuai dengan pernyataan Assael (2001), persepsi konsumen terhadap produk dapat menjadi pertimbangan konsumen dalam menentukan pilihan produk mana yang akan dibeli, semakin tinggi persepsi maka konsumen akan semakin tertarik untuk membeli, dalam hal ini faktor-faktor yang membentuk produk diantaranya rasa, harga, dan pelayanan. Kemudian pada variabel X4 (kemasan yang menarik), dengan nilai faktor loading sebesar 0,747 , variabel X6 (kesesuaian harga dengan produk) dengan nilai faktor loading sebesar 0,544, variabel X17 (pelayanan yang akurat yang meliputi bebas dari kesalahan) dengan nilai faktor loading sebesar 0,418. Variabel-variabel tersebut merupakan faktor yang menjadi pertimbangan konsumen dalam pengambilan keputusan pembelian di Starbucks Beachwalk Mall, Badung.

Menurut penelitian Ramdhani (2005), penyajian produk yang menarik merupakan variabel yang menjadi pertimbangan penting dalam indikator kualitas produk. Dilihat dari hasil penelitian yang diperoleh variabel penyajian kemasan produk yang menarik dan kesesuaian harga dengan produk merupakan variabel yang sangat dipertimbangkan dalam pengambilan keputusan pembelian.

c. Faktor 3 (kombinasi promosi, harga, lokasi)

Waktu promosi yang tepat adalah lamanya promosi yang dilakukan oleh perusahaan sesuai dengan harapan konsumen, keterjangkauan harga produk, tempat parkir yang luas, aman, dan nyaman merupakan faktor-faktor yang dipertimbangkan konsumen dalam pengambilan keputusan 
pembeliannya di Starbucks Beachwalk Mall, Badung. . (Eigenvalue yang ditunjukkan sebesar 1.760). Variabel-variabel yang tercakup ke dalam faktor-faktor ini mampu menjelaskan keragaman variabel sebesar 8,38\% jika dilihat dari faktor loading. Variabel X14 (waktu promosi yang tepat adalah lamanya promosi yang dilakukan oleh perusahaan sesuai dengan harapan konsumen) merupakan faktor yang dipertimbangkan konsumen dalam pengambilan keputusan pembeliannya di Starbucks Beachwalk Mall, Badung dengan menunjukkan nilai sebesar 0,737. Kemudian pada variabel X5 (Keterjangkauan harga), dengan nilai faktor loading sebesar 0,615, variabel X10 (Tempat parkir yang luas, aman, dan nyaman) dengan nilai faktor loading sebesar 0,610. Variabel-variabel tersebut merupakan faktor yang menjadi pertimbangan konsumen dalam pengambilan keputusan pembelian di Starbucks Beachwalk Mall, Badung.

\section{d. $\quad$ Faktor 4 (kombinasi harga dan lokasi)}

Kesesuaian harga dengan kualitas produk, visibilitas, yaitu lokasi usaha dapat dilihat dengan jelas dari jarak pandang normal merupakan faktor-faktor yang dipertimbangkan konsumen dalam pengambilan keputusan pembeliannya di Starbucks Beachwalk Mall, Badung. (Eigenvalue yang ditunjukkan sebesar 1.449). Variabel-variabel yang tercakup ke dalam faktor-faktor ini mampu menjelaskan keragaman variabel sebesar $6,89 \%$ jika dilihat dari faktor loading. Variabel X7 (kesesuaian harga dengan kualitas produk), dengan nilai faktor loading sebesar 0,742. Kualitas produk dengan harga yang diberikan Starbucks merupakan faktor yang dipertimbangkan konsumen. Kemudian variabel X9 (visibilitas, yaitu lokasi usaha dapat dilihat dari jarak pandang normal) dengan nilai faktor loading sebesar 0,648. Variabel-variabel tersebut merupakan faktor yang menjadi pertimbangan konsumen dalam pengambilan keputusan pembelian di Starbucks Beachwalk Mall, Badung.

e. Faktor 5 Pelayanan

Adanya pendukung pelayanan lainnya yang cukup seperti ruang tunggu ber-AC, kebersihan dan lain-lain. Kemudahan mendapatkan pelayanan, misalnya banyaknya petugas yang melayani dan banyaknya fasilitas pendukung seperti computer merupakan faktor-faktor yang dipertimbangkan konsumen dalam pengambilan keputusan pembeliannya di Starbucks Beachwalk Mall, Badung. (Eigenvalue yang ditunjukkan sebesar1.416). Variabel-variabel yang tercakup ke dalam faktor-faktor ini mampu menjelaskan keragaman variabel sebesar 6,74\% jika dilihat dari faktor loading. Variabel X21 (adanya pendukung pelayanan lainnya yang cukup seperti ruang tunggu ber-AC, kebersihan dan lain-lain), dengan nilai faktor loading sebesar 0,768. Adanya fasilitas pendukung seperti AC yang diberikan Starbucks merupakan faktor yang dipertimbangkan konsumen. Kemudian variabel X19 (kemudahan mendapatkan pelayanan, misalnya banyaknya petugas yang melayani dan banyaknya fasilitas pendukung seperti komputer) dengan nilai faktor loading sebesar 0,742. Variabel-variabel tersebut merupakan faktor yang menjadi pertimbangan konsumen dalam pengambilan keputusan pembelian di Starbucks Beachwalk Mall, Badung. 
f. $\quad$ Faktor 6 Produk

Rasa Kopi yang enak, keistimewaan produk kopi merupakan faktor-faktor yang dipertimbangkan konsumen dalam pengambilan keputusan pembeliannya di Starbucks Beachwalk Mall, Badung. (Eigenvalue yang ditunjukkan sebesar 1.173). Variabel-variabel yang tercakup ke dalam faktor-faktor ini mampu menjelaskan keragaman variabel sebesar 5,58\% jika dilihat dari faktor loading. Variabel X1 (rasa Kopi yang enak), dengan nilai faktor loading sebesar 0,827. Rasa kopi yang enak yang diberikan Starbucks merupakan faktor yang sangat penting yang menjadi pertimbangan konsumen. Kemudian variabel X2 (keistimewaan produk kopi) dengan nilai faktor loading sebesar 0,591. Variabel-variabel tersebut merupakan faktor yang menjadi pertimbangan konsumen dalam pengambilan keputusan pembelian di Starbucks Beachwalk Mall, Badung.

g. Faktor 7 (promosi dan pelayanan)

Kuantitas promosi adalah nilai atau jumlah promosi penjualan yang diberikan konsumen sesuai dengan harapan konsumen, pelayanan dilakukan dengan sopan dan ramah merupakan faktor-faktor yang dipertimbangkan konsumen dalam pengambilan keputusan pembeliannya di Starbucks Beachwalk Mall, Badung. (Eigenvalue yang ditunjukkan sebesar 1.017). Variabel-variabel yang tercakup ke dalam faktor-faktor ini mampu menjelaskan keragaman variabel sebesar 5,13\% jika dilihat dari faktor loading. Variabel X13 (kuantitas promosi adalah nilai atau jumlah promosi penjualan yang diberikan konsumen sesuai dengan harapan konsumen), dengan nilai faktor loading sebesar 0,846. Promosi penjualan sesuai dengan harapan konsumen yang diberikan Starbucks merupakan faktor penting yang menjadi pertimbangan konsumen. Kemudian variabel X18 (pelayanan dilakukan dengan sopan dan ramah) dengan nilai faktor loading sebesar 0,425. Variabel-variabel tersebut merupakan faktor yang menjadi pertimbangan konsumen dalam pengambilan keputusan pembelian di Starbucks Beachwalk Mall, Badung.

h. Faktor 8 (kombinasi pelayanan dan promosi)

Kenyamanan dalam memperoleh pelayanan, berkaitan dengan lokasi, ruang tempat pelayanan, tempat parkir, ketersediaan informasi dan lain-lain, frekuensi promosi adalah jumlah promosi penjualan yang dilakukan cukup banyak melalui media promosi merupakan faktor-faktor yang dipertimbangkan konsumen dalam pengambilan keputusan pembeliannya di Starbucks Beachwalk Mall, Badung. (Eigenvalue yang ditunjukkan sebesar 1.000). Variabel-variabel yang tercakup ke dalam faktor-faktor ini mampu menjelaskan keragaman variabel sebesar 4,76\% jika dilihat dari faktor loading. Variabel X20 (kenyamanan dalam memperoleh pelayanan, berkaitan dengan lokasi, ruang tempat pelayanan, tempat parkir, ketersediaan informasi dan lain-lain), dengan nilai faktor loading sebesar 0,591. Kenyamanan dalam mendapatkan pelayanan yang diberikan Starbucks merupakan faktor penting yang menjadi pertimbangan konsumen. Kemudian variabel X11 (frekuensi promosi adalah jumlah promosi penjualan yang dilakukan cukup banyak melalui media promosi) dengan nilai 
faktor loading sebesar 0,573. Variabel-variabel tersebut merupakan faktor yang menjadi pertimbangan konsumen dalam pengambilan keputusan pembelian di Starbucks Beachwalk Mall, Badung.

i. Ketepatan Model

Langkah terakhir dalam analisis faktor adalah penentuan ketepatan model. Model analisis faktor perlu diuji ketepatannya sehingga dapat diketahui apakah model dapat menjelaskan dengan baik. Dasar dari pengujian ketepatan model adalah dengan melihat persentase jumlah residual yaitu perbedaan korelasi yang diamati dengan korelasi berdasarkan estimasi faktor matriks. Hasil untuk ketepatan model menujukkan nilai residual sebesar 95 (45\%) dengan nilai absolute > 0,05. Hasil ini menjelaskan bahwa model dapat diterima dengan ketepatan model sebesar $65 \%$.

\section{KESIMPULAN DAN SARAN}

\section{Kesimpulan}

1) Faktor-faktor bauran pemasaran dan pelayanan yang mempengaruhi keputusan pembelian konsumen di Starbucks Beachwalk Mall, Badung adalah : (1) Produk (penampilan penyajian produk yang menarik, kemasan yang menarik, rasa kopi yang enak, keistimewaan produk kopi) ; (2) Harga (adanya diskon harga produk, keterjangkauan harga, kesesuaian harga dengan kualitas produk) ; (3) Lokasi (Akses lokasi mudah dijangkau, tempat parkir yang luas, aman, dan nyaman, lokasi usaha dapat dilihat dengan jelas) ; (4) Promosi (ketepatan sasaran promosi, kualitas promosi yang menarik minat konsumen untuk membeli, waktu promosi yang tepat, kuantitas promosi sesuai dengan harapan konsumen, promosi penjualan cukup banyak melalui media promosi) ; (6) Pelayanan (pelayanan yang tepat waktu, pelayanan yang akurat, adanya pendukung pelayanan seperti ruang tunggu ber-AC, kebersihan dan lain-lain, kemudahan mendapatkan pelayanan, pelayanan dilakukan dengan sopan dan ramah, kenyamanan dalam memperoleh pelayanan).

2) Variabel-variabel yang dominan mewakili setiap faktor yang mempengaruhi pertimbangan keputusan pembelian konsumen pada Starbucks Beachwalk Mall, Badung adalah: (1) Produk (rasa kopi yang enak dan penampilan penyajian produk yang menarik) ; (2) Harga (kesesuaian harga dengan kualitas produk); (3) Promosi (promosi tepat sasaran, waktu promosi yang tepat, dan nilai atau jumlah promosi penjualan yang diberikan kepada konsumen sesuai dengan harapan konsumen) ; (4) Lokasi (kemudahan akses lokasi) ; (5) Pelayanan (adanya pendukung pelayanan seperti ruang tunggu ber-AC, kebersihan, dan kenyamanan pelayanan).

\section{Saran}

Untuk meningkatkan kinerja perusahaan maka perlu memperhatikan faktor-faktor dominan dalam bauran pemasaran dan pelayanan, yaitu : (1) Produk (rasa kopi yang enak dan penampilan penyajian produk yang menarik) ; (2) Harga (kesesuaian harga dengan kualitas produk) ; (3) Promosi (promosi tepat sasaran, waktu promosi yang tepat, dan nilai atau jumlah promosi penjualan yang diberikan kepada 
konsumen sesuai dengan harapan konsumen) ; (4) Lokasi (kemudahan akses lokasi) ; (5) Pelayanan (adanya pendukung pelayanan seperti ruang tunggu ber-AC, kebersihan, dan kenyamanan pelayanan).

\section{DAFTAR PUSTAKA}

Dewantoro, K. 2013. Pengaruh Bauran Pemasaran Terhadap Keputusan Pembelian. Skripsi. Fakultas Ekonomi. Universitas Negeri Surabaya.

Ramdhani, Y. 2005. Analisis Proses Keputusan Konsumen dalam Pembelian Makanan Siap Saji di Kentucky Fried Chicken cabang Padjajaran, Bogor dan Implikasinya terhadap Bauran Pemasaran. Skripsi. Bogor: Program Studi Agribisnis, Fakultas Pertanian, Institut Pertanian Bogor.

Sudarsana, I. N. 2007. Faktor-Faktor yang dipertimbangkan Konsumen dalam Keputusannya Berbelanja pada Supermarket Delta Dewata Ubud Gianyar. Fakultas Ekonomi. Universitas Udayana.

Malholtra, N. K. 1999. Marketing Research. New Jersey: Prentice Hall, Inc

Nurdiansyah, D. 2014. Uji Validitas dan Reliabilitas. www.stasdata.my.id/2011/12/uji-validitas-danreliabilitas.html. Diakses 9 September 2017

Sugiyono. 2008. Metode Penelitian Bisnis. Bandung: Alphabeta. 